\title{
Composites Based on Waste Printed Circuit Boards (WPCB) and Waste Polypropylene ${ }^{\dagger}$
}

\author{
Elena Ramona Andrei 1, Madalina Elena David 1,2,*, Ramona Marina Grigorescu 1, Paul Ghioca 1, \\ Lorena Iancu 1,2, Rodica-Mariana Ion 1,2, Mircea Filipescu 1, Raluca Gabor 1, \\ Cristian Andi Nicolae ${ }^{1}$, Bogdan Spurcaciu ${ }^{1}$ and Laurentiu Marin ${ }^{1}$ \\ 1 National Institute for Research \& Development in Chemistry \& Petrochemistry - ICECHIM, 202 Splaiul \\ Independentei, 060021 Bucharest, Romania; andreiramona@hotmail.com (E.R.A.); \\ rmgrigorescu@gmail.com (R.M.G.); pghioca@yahoo.com (P.G.); lorenna77ro@yahoo.com (L.I.); \\ rodica_ion2000@yahoo.co.uk (R.-M.I.); mfilipescu3@gmail.com (M.F.); ralucagabor@yahoo.com (R.G.); \\ ca_nicolae@yahoo.com (C.A.N.); bogdansssss@hotmail.com (B.S.); andree_marr@yahoo.co.uk (L.M.) \\ 2 Valahia University, Doctoral School of Materials Engineering Department, 13 Aleea Sinaia, 130004 \\ Targoviste, Romania \\ * Correspondence: madalina.david@icechim.ro \\ † Presented at the 15th International Symposium "Priorities of Chemistry for a Sustainable Development" \\ PRIOCHEM, Bucharest, Romania, 30th October-1st November 2019.
}

Published: 11 October 2019

Keywords: waste printed circuit boards (WPCB); waste polypropylene; elastomers; reinforced composites

The high amount of plastics, which are durable, lightweight, and cheap materials, is one of the major current ecological concerns. The recycling of waste printed circuit boards (WPCB) has been an increasingly debated issue in the last two decades at government level and worldwide as they have a particularly harmful polluting effect (e.g., heavy metals and brominated compounds used as fire retardants) due to their non-biodegradability. WPCB recycling by blending with polypropylene waste (RPP) can be considered as a potential method with both technical and ecological implications. The research aimed to obtain impact-strength RPP composites using block-copolymers as impact modifiers and WCPB as the reinforcing agent. After the collection, the WPCB were ground into powder less than $1 \mathrm{~mm}$ size. The metallic parts $(\mathrm{Cu})$ were removed by leaching and solvent evaporation. The waste polypropylene was collected from industrial injected boxes (density 0.96$0.99 \mathrm{~g} / \mathrm{cm}^{3}$; melt flow index at $190{ }^{\circ} \mathrm{C}$ and $5 \mathrm{~kg}$ of $6 \mathrm{~g} / 10 \mathrm{~min}$, tensile strength $2.06 \mathrm{MPa}$, elongation at break $2.83 \%$, and IZOD impact strength at $23{ }^{\circ} \mathrm{C}$ of $6 \mathrm{~kJ} / \mathrm{m}^{2}$ ). As impact modifiers, a styrene-butadiene block-copolymer (SBS, Europrene $161 \mathrm{C}$ ) and a maleinized and hydrogenated block-polymer (SEBS-MA, Kraton FG 1901X) were used. The composites were obtained through melt compounding and the tensile and impact properties of the composites were determined. The composition influence on mechanical and impact properties of the RPP-elastomers-WPCB composites highlighted that impact strength improvement is controlled by elastomer domain size, their dispersion degree into the polyolefin matrix, and the compatibility between components. $\mathrm{WCPB}$ act as a reinforcing agent of the RPP matrix. Obtaining composites based on polyolefin waste and WPCB can be considered as a potential method for removing unused plastics from the environment. The new materials produced can be used for: different technical benchmarks for the construction industry, hangers, transport shuttles, and industrial containers, amongst other uses. 
Acknowledgments: This paper was supported by a grant from the Romanian Ministry of Research and Innovation, CCCDI-UEFISCDI, project number PN-III-P1-1.2-PCCDI-2017-0652/84 PCCDI/2018, within PNCDI III and by project no. PN.19.23.03.01.04, contract no. 23N/2019 within the Nucleu Program and 5PS/2019.

(C) 2019 by the authors. Licensee MDPI, Basel, Switzerland. This article is an open access article distributed under the terms and conditions of the Creative Commons Attribution (CC BY) license (http://creativecommons.org/licenses/by/4.0/). 